\title{
Effect of Thoracic Epidural Analgesia in Patients of Traumatic Multiple Rib Fractures withNeurotrauma: A Study Done in a SpecializedNeuro-ICU in Bangladesh
}

\author{
SM Ahsanul Habib ${ }^{1}$, Lutful Aziz ${ }^{2}$, Arifa Sultana ${ }^{3}$, Taneem Mohammad ${ }^{4}$, Kaisar Haroon ${ }^{5}$ \\ ${ }^{1}$ Senior Registrar, Department of Anaesthesia, ICU and Pain Medicine, Apollo Hospitals, Dhaka, Bangladesh; ${ }^{2}$ Senior \\ Consultant \& Coordinator, Department of Anaesthesia, ICU and Pain Medicine, Apollo Hospitals, Dhaka, Bangladesh; \\ ${ }^{3}$ Senior Registrar, Department of Obstetrics \& Gynaecology, Apollo Hospitals, Dhaka, Bangladesh; ${ }^{4}$ Anaesthesiologist, \\ Department of Anaesthesia, Analgesia, Palliative and Intensive Care Medicine, Dhaka Medical College Hospital, \\ Dhaka, Bangladesh; ${ }^{5}$ Assistant Professor, Department of Clinical Neurosurgery, National Institute of \\ Neurosciences \& Hospital, Dhaka, Bangladesh
}

[Received: 12 November 2019; Accepted: 2 December 2019; Published: 1 January 2020]

\begin{abstract}
Background: Epidural analgesia provides better pain relief and improves pulmonary function in head or spine injury patients with multiple rib fractures. Objective: This present study was aimed to see the effects of thoracic epidural analgesia in patients of rib fractures with neurotrauma admitted at intensive care unit. Methodology: This clinical trial was performed in the Neuro-ICU of Apollo Hospitals, Dhaka, Bangladesh between January 2013 and December 2014 for a period of two years. The patients who were admitted in the Neuro ICU with the head or spine injury with rib fracture with the age of more than 18 years in both male and female were selected as study population. Thoracic epidural analgesic (TEA) was given through percutaneous approaches. Comparison of pain ratings were done before and after epidural analgesic administration as well as between early and delayed epidural analgesia. Monitoring was done to identify if any complications occur either due to the procedure or anaesthetic or analgesic drug itself. Results: A total number of 100 patients were recruited for this study. Following thoracic epidural analgesia (TEA), pain rating improved in $76.0 \%$ cases; coughing was diminished in $78.0 \%$ cases, while suctioning was improved in $68.0 \%$ cases. Besides, physiotherapy and positioning improvement were found in $68.0 \%$ cases and $72.0 \%$ cases respectively, while chest expansion was improved in $88.0 \%$ cases. Thoracic epidural analgesia was given soon after injury and had given a significant improvement compared with the patients who got the delayed TEA considering in ventilation $(78.0 \%$ vs. $22.0 \%)$ and in mobilization $(72.0 \%$ vs. $32.0 \%)(\mathrm{p}<0.001)$; however, weaning from the ventilator or length of ICU stay had no difference among those two groups. Moreover, pneumonia, acute respiratory distress syndrome (ARDS) and mortality reported more in those who got delayed TEA $(\mathrm{p}<0.05)$. Complications included the misplacement of catheter $(2.0 \%)$, hypotension $(8.0 \%)$, bradycardia $(6.0 \%)$ and respiratory depression $(2.0 \%)$. Conclusion: Thoracic epidural analgesia which is given soon after injury has showed better prognosis and outcomes in the patients suffering from multiple rib fractures with neurotrauma. [Journal of National Institute of Neurosciences Bangladesh, 2020;6(1): 24-28]
\end{abstract}

Keywords: : Rib fracture; neurotrauma; epidural analgesia; outcome;neuro-ICU

Correspondence: Dr. SM Ahsanul Habib,Senior Registrar, Department of Anaesthesia, ICU and Pain Medicine, Apollo Hospitals, Dhaka, Bangladesh; Cell no.: +8801711199577; Email: smahabib@yahoo.com

Conflict of interest: There is no financial conflict of interest relevant to this paper to disclose.

Funding agency: This project was not funded by any group, organization or institution.

Contribution to authors: SMA Habib and L Aziz were involved in concept and design of the study, SMA Habib, A Sultana, T Mohammad were involved in data collection, SMA Habib and K Haroon did data compilation, processing and analysis, while SMA Habib, L Aziz, A Sultana, T Mohammad and K Haroon were equally involved in the literature search, compilation, manuscript writing and revision.

How to cite this article: Habib SMA, Aziz L, Sultana A, Mohammad T, Haroon K. Effect of Thoracic Epidural Analgesia in Patients of Traumatic Multiple Rib Fractures with Neurotrauma: A Study Done in a Specialized Neuro-ICU in Bangladesh. J NatlInstNeurosci Bangladesh, 2020;6(1): 24-28

Copyright: (C2020. Habib et al. Published by Journal of National Institute of Neurosciences Bangladesh. This article is published under the Creative Commons CC BY-NC License (https://creativecommons.org/licenses/by-nc/4.0/). This license permits use, distribution and reproduction in any medium, provided the original work is properly cited, and is not used for commercial purposes. 


\section{Introduction}

Although there is a declining trend in the global burden of diseases (GBD) due to injuries, resulting from recent advances in injury research and prevention efforts, trauma remains one of the major causes of morbidity and mortality in Bangladesh, like other low-income coutries ${ }^{1}$. Evidence suggests that this is mostly due to road traffic accidents (RTA) and falls from heights ${ }^{1,2}$. Rib fractures are very common injuries among trauma patients. Simultaneous neurotrauma has been observed in those patients, too ${ }^{3,4}$. Rib fracture occurred about $10 \%$ of blunt trauma patients and one third of them develop pulmonary complications ${ }^{4}$. Moreover, patients with 2-4 rib fractures have mortality rate of $5 \%{ }^{4}$. Pain associated with a single rib fracture is relatively easy to control; however, the severe pain in multiple rib fractures is very critical to manage and may lead to decreased pulmonary function, increased hospital length of stay, and increased healthcare expenditure ${ }^{4,5}$. Management of the patient with chest wall injury is directed allowing adequate oxygenation and ventilation ${ }^{4}$. Leone et $\mathrm{al}^{6}$ found pulmonary contusion with rib fractures in $29.0 \%$ of head trauma patients and the association may increase the chances of mortality as high as $80.0 \%$. Early and prompt management of such associated injuries improve survival ${ }^{4,5}$. Unfortunately, evaluation for these associated injuries is often overshadowed by emphasis on head injury ${ }^{4}$.

Western research showed three patient management practices $^{4,5,7}$, which had significant success in influencing outcomes and preventing complications in such patients: rapid mobilization, respiratory support, and proper pain management. Management of these patients is, therefore, focused on achieving adequate analgesia and clearance of pulmonary secretions ${ }^{4}$. Previous studies showed thoracic epidural analgesia (TEA) as a standard of care for pain management for patients with neurotrauma and multiple rib fractures and as well as an impactful modality in patients' recovery ${ }^{5,7}$. Evidence suggests thoracic epidural analgesia as an effective method, still it may have some side effects ${ }^{5,8-10}$. Hence, several western studies have demonstrated that epidural analgesia provides better pain relief and improves pulmonary function in patients of neurotrauma along with multiple rib fractures. Unfortunately, we do not have such evidence in our country. Therefore, this present study was aimed to see the effects of epidural analgesia in patients' condition as well as its complications in patients admitted with multiple rib fractures and neurotrauma in a specialized tertiary level urban hospital setting in Bangladesh.

\section{Methodology}

This clinical trial was performed in the Neuro-ICU of Apollo Hospitals, Dhaka, Bangladesh. This hospital was one of the largest and state-of-art facilities in the country. This present study was conducted from January 2013 and December 2014 for a period of 2 years. Patients were selected based on the following inclusion and exclusion criteria from the patients admitted in the Neuro-ICU of the hospital during the study period. Patient who had neuro-trauma with at least 2 ribs fracture, unconscious patients and patients having no contraindication for epidural catheter placement were selected as study population. Patients with neurotrauma but having no rib fracture or single rib fracture were excluded from this study. In this study,two age groups were selected: patients of 20 to 45 years as young group and above 45 years as older group ${ }^{11}$. Demographic and clinical data were collected which were age, causes of trauma, nature of trauma, types of neuro-trauma associated with rib fracture, and conscious level of the patient by using Glasgow Coma scale (GCS).Thoracic epidural analgesic (TEA) was given mostly through percutaneous approaches in the thoracic epidural space by using needle guided by surface anatomic landmarks ${ }^{12}$. The prominent $\mathrm{C} 7$ spinous process, the scapular spine (T3), and the inferior border of the scapula (T7) were useful landmarks to approximate the puncture site to the intended segment. Use of these landmarks may vary among patients. When performing an upper thoracic epidural placement in an obese patient, the scapula might be difficult to identify. Using the prominent $\mathrm{C} 7$ spinous process to estimate the targeted thoracic segment in obese patients might be useful. If conventional midline approach to the thoracic epidural space was found difficult, a paramedian approach was taken to place the needle consistently at other thoracic epidural segments above T11. It was preferred that patients were placed in a lying lateral position with neck and upper back flexion. Epidural catheter was placed and the primary choices of analgesic agents was infused for thoracic epidural analgesia which included local anesthetic alone. Bupivacaine hydrochloride $(0.125 \% \mathrm{w} / \mathrm{v})$ was infused through syringe pump with a rate of 2 to $4 \mathrm{ml}$ per hour according to the patient and placement of catheter. In this study, it was used the Wong-Baker FACES ${ }^{\circledR}$ Pain Rating Scale to do pain measurement ${ }^{13}$. Comparison of pain ratings were done before and after epidural analgesic administration. Besides, comparison between the effects of early insertion and delayed insertion of epidural analgesic were also performed. Close 
observation was done to identify any epidural catheter related complications or complications for the anaesthetic or analgesic drug itself. Data were analyzed by using SPSS (Statistical Package for Social Science) version 16.0. Comparison between groups were done by unpaired t-test, while categorical data were analyzed with Chi-square test. This study protocol was approved by the Departmental Ethics Review Board of Department of Anaesthesia, ICU \& Pain Medicine, Apollo Hospitals, Dhaka, Bangladesh.

\section{Results}

The patients of neurotrauma with rib fractures were mainly young adult (68.0\%) and the main cause of

Table 1: Demographic and Clinical Evaluation of the patients

\begin{tabular}{lcc}
\hline Variables & Frequency & Percent \\
\hline Age Group & 102 & 68 \\
20 to 45Years & 48 & 32 \\
More Than 45 Years & & \\
Cause of Trauma & 126 & 82 \\
RTA & 15 & 10 \\
Fall from height & 12 & 8 \\
Assault & & \\
Neurotrauma & 57 & 38 \\
ICH & 63 & 42 \\
Skull bone fracture & 30 & 20 \\
Diffuse axonal injury & & \\
Rib Fractures & 120 & 80 \\
2 to 3 & 30 & 20 \\
More Than 3 & & \\
Other Injuries & 99 & 66 \\
Long bone fracture & 36 & 24 \\
Facial injury & 15 & 64 \\
Internal surgical injury & & 610 \\
GCS & 69 & \\
Upto 7 & & \\
7 & & \\
\hline
\end{tabular}

trauma $(82.0 \%)$ was road traffic accident (RTA). Other causes included accidental fall $(10.0 \%)$ and physical assault (8.0\%). Among the neurotrauma intracranial haemorrhage $(\mathrm{ICH})$ was $48 \%$, skull bone fracture $32.0 \%$ and diffuse axonal injury $20 \%$. $80 \%$ of the patients had 2-3 rib fractures, while the other $20.0 \%$ more than 3 ribs fractures. Complicated injuries reported as long bone fracture in $66.0 \%$, facial injury in $24.0 \%$, other internal abdominal injury in $10.0 \%$. On examination, conscious level as measured by Glasgow Coma Scale (GCS) was found above 7 in $78.0 \%$, while upto 7 in $22.0 \%$ cases (Table 1 ).

Following thoracic epidural analgesia (TEA) pain rating improved in $76 \%$ cases, coughing diminished in $78 \%$ cases, while suctioning improved in $68 \%$ cases. Besides, physiotherapy and positioning of the patients improved in $68 \%$ and $72 \%$ cases respectively, while chest expansion improved in $88 \%$ cases (Table 2 ).

Thoracic epidural analgesia given soon after injury caused a significant improvement than who got a delayed TEA considering in ventilation (78\% vs. $22 \%$ ) and in mobilization $(72 \%$ vs. $32 \%)(p<0.001)$; whereas weaning from ventilator or length of ICU stay had no difference among those two groups (Table 3).

Among the unadjusted outcomes, Pneumonia developed in only $4.0 \%$ cases, where $66.67 \%$ developed in those who got delayed TEA. Similarly, ARDS also reported in $6.0 \%$ cases, of which $55.56 \%$ got delayed TEA. Mortality reported in $8.0 \%$ cases, as $58.33 \%$ were in those who got delayed TEA $(\mathrm{p}<0.05)$ (Table 4).

Complications included misplacement of catheter $(2 \%)$, hypotension $(8 \%)$, bradycardia $(6 \%)$ and respiratory depression $(2.0 \%)$ (Table 5).

Table 2: Pain and other symptoms before and after infusion of epidural analgesic $(n=50)$

\begin{tabular}{lccccccc}
\hline & \multicolumn{3}{c}{$\begin{array}{c}\text { Pain score in } \\
\text { patients }\end{array}$} & \multicolumn{1}{c}{ Improvement of the conditions of the patients } \\
\cline { 2 - 8 } & $0-2$ & $>2$ & $\begin{array}{c}\text { Coughing } \\
\text { Diminished }\end{array}$ & $\begin{array}{c}\text { Suction } \\
\text { Functioning }\end{array}$ & $\begin{array}{c}\text { Physiotherapy\& } \\
\text { Spirometry }\end{array}$ & Positioning & $\begin{array}{c}\text { Respiration } \\
\text { /Chest expansion }\end{array}$ \\
Before Epidural & $30 \%$ & $70 \%$ & $22 \%$ & $32 \%$ & $32 \%$ & $28 \%$ & $12 \%$ \\
After Epidural & $76 \%$ & $24 \%$ & $78 \%$ & $68 \%$ & $68 \%$ & $72 \%$ & $88 \%$ \\
\hline
\end{tabular}


Table 3: Adjusted Outcome of the Patients

\begin{tabular}{|c|c|c|c|c|c|c|c|}
\hline \multirow[t]{2}{*}{$\begin{array}{l}\text { Time of } \\
\text { Epidural }\end{array}$} & \multirow[t]{2}{*}{$\begin{array}{l}\text { Ventilation } \\
\text { improved }\end{array}$} & \multicolumn{2}{|c|}{$\begin{array}{l}\text { Weaning for } \\
\text { ventilator }\end{array}$} & \multicolumn{2}{|c|}{ Mobilization } & \multicolumn{2}{|c|}{$\begin{array}{c}\text { Length of ICU } \\
\text { stay }\end{array}$} \\
\hline & & 0-3 Days & 0-3 Days & $<2$ Days & $>2$ Days & $<8$ Days & >8 Days \\
\hline $\begin{array}{l}\text { Immediate } \\
\text { After Injury }\end{array}$ & $78.0 \%$ & $52.0 \%$ & $52.0 \%$ & $72.0 \%$ & $28.0 \%$ & $48.0 \%$ & $52.0 \%$ \\
\hline $\begin{array}{l}2 \text { to } 3 \text { days } \\
\text { after injury }\end{array}$ & $22.0 \%$ & $46.0 \%$ & $46.0 \%$ & $32.0 \%$ & $68.0 \%$ & $44.0 \%$ & $56.0 \%$ \\
\hline
\end{tabular}

Table 4: Unadjusted outcome of the patients

\begin{tabular}{lccc}
\hline Outcome & \multicolumn{2}{c}{ Time of Epidural } & Total \\
\cline { 2 - 4 } & Immediate After Injury & 2 to 3 days after injury & \\
\hline Pneumonia & $2(33.33 \%)$ & $4(66.67 \%)$ & $6(100.0 \%)$ \\
ARDS & $4(44.44 \%)$ & $5(55.56 \%)$ & $9(100.0 \%)$ \\
Mortality & $5(41.67 \%)$ & $7(58.33 \%)$ & $12(100.0 \%)$ \\
\hline
\end{tabular}

Table 4: Unadjusted outcome of the patients

\begin{tabular}{cccccc}
\hline \multicolumn{2}{c}{ Due to epidural procedure } & & \multicolumn{2}{c}{ Due to effects of the drug } \\
\cline { 1 - 2 } \cline { 5 - 6 } Dural Puncture & Misplacement of catheter & & Hypotension & Bradycardia & Respiratory depression \\
\hline 0 & $3(2 \%)$ & $12(8 \%)$ & $9(6 \%)$ & $3(2 \%)$ \\
\hline
\end{tabular}

\section{Discussion}

Previous western studies have showed that thoracic epidural analgesia gives better analgesia and outcome without CNS depression, repeat or multiple injection as well as ensure bilateral analgesia, in comparison to other procedures like paravertebral block or intravascular analgesia, which has resulted in CNS depression, ipsilataral analgesia, cough suppression and hypotension ${ }^{9,14}$. However, it has got some contraindications like coagulopathy, spinal injury, hypotension $^{5,7,9,10}$.

Road traffic accident (RTA) is the leading causes of trauma in this country and occurs most commonly among the younger population. Accidental fall and assault also occur in a large number of cases. The present study is also in agreement with those epidemiological findings ${ }^{1,2}$. Most of the patients belonged to young age group (20 to 25 years). Previous studies have showed that the vulnerability to complications and poor outcomes depend on age. Holcomb et $\mathrm{al}^{11}$ showed that patients above 45 years have poor outcome and serious consequences, while Testerman ${ }^{15}$ showed that younger patients are prone to more complications and poor outcomes. However, no correlation is shown in this study.

Glasgow coma scale (GCS) is a reflection of the severity of the original head and chest injury, and it may also reflect the cumulative secondary injury to the brain and hence, the importance of earlier management. It is impossible to determine the contribution of each of these factors to the outcome from the design of this study and more studies are required to evaluate the importance of these factors. However, in this study, it has been observed that the patients who have multiple rib fractures with the GCS score up to 7 have poor outcomes, which is in agreement with that of Harington et $\mathrm{al}^{3}$ and Mezue et $\mathrm{al}^{16}$.

Worthley ${ }^{17}$ has reported that pain relief with epidural analgesia is dramatic and is not associated with sedation. During a 6-year period, 161 patients with chest trauma are treated with thoracic epidural analgesia. The group have an increase in mean vital capacity after analgesia has been given. As a result of proper thoracic epidural pain management, patients are more alert and cooperative and thus able to participate in increased activities such as turning, getting up, and physiotherapy, which is also evident in this study.

Efficient pain relief with continuous thoracic epidural analgesia allow good mobilization and physiotherapy management without central sedation and impairment of the cough reflex, thus preventing pulmonary atelectasis and infection ${ }^{3}$. Similar results are evident in this study. Inadequate ventilation results from mechanical instability and subsequent splinting of the involved side of the chest, which is unavoidable because of pain. In this study, respiration and chest 
expansion improved dramatically after thoracic epidural, $88 \%$ cases. Besides, pain during positioning also decreased after thoracic epidural analgesia. This study results are supported by the several western studies ${ }^{3,5,16}$.

In case of multiple rib fracture accompanied with neurotrauma chest complications and mortality are $\operatorname{high}^{3,11,15}$. In this study,pneumonia developed in 6 patients (4\%) cases, ARDS in 9 patients $(6 \%)$ and death in 12 patient (8\%); but the number is less in those who got epidural analgesia soon after injury. However, the percentage of complications and mortality could be more if the sample size is larger.

There are some limitation of this present study. In the present study, the proportion of patient presenting with concomitant chest injuries was high considering the short duration of data collection. This is because the hospital of the present study is a major trauma referral center having specialized neuro-ICU. This study is also limited by the small number of patients. The mortality could have been affected by selection bias, since some injured patients may have been treated at other small hospitals and got TEA after a long delay. Another limitation was that the data did not include information about use of any safety devices while driving or at workplace.

\section{Conclusion}

It can be concluded that application of thoracic epidural analgesia (TEA) has given a better prognosis and outcomes in the patients suffering from multiple rib fractures with neurotrauma.Furthermore, thoracic epidural analgesia (TEA) can be a standard of care in those cases.In patients with multiple rib fractures who are associated with neurotrauma, partial outcomes depend on appropriate management of pain. By adopting this TEA among the patients has a good impact in the improvement of the patients.

\section{References}

1. Haagsma JA, Graetz N, Bolliger I, et al. The global burden of injury: incidence, mortality, disability-adjusted life years and time trends from the Global Burden of Disease study 2013. InjPrev 2016; 22(1):3-18.

2. World Health Organization (WHO). Injuries and violence: the facts 2014. Geneva: WHO; 2014. p.2-9.

3. Harrington DT, Phillips B, Machan J, et al. Factors associated with survival following blunt chest trauma in older patients: results from a large regional trauma cooperative. Arch Surg 2010;145(5):432-437.

4. Simon BJ, Cushman J, Barraco R, et al. Pain management guidelines for blunt thoracic trauma. J Trauma 2005; 59(5):1256-1267.

5. Manion SC, Brennan TJ. Thoracic epidural analgesia and acute pain management. Anesthesiology 2011;115(1):181-188.

6.Leone M, Albanèse $\mathrm{J}$, Rousseau $\mathrm{S}$, et al. Pulmonary contusion in severe head trauma patients: Impact on gas exchange and outcome. Chest 2003;124(6):2261-2266.

7. Macintyre PE, Scott DA, Schug SA, Visser EJ, Walker SM. eds.Acute Pain Management: Scientific Evidence. 3rd Ed. Melbourne: ANZCA \& FPM; 2010. p.47-50.

8. Clemente A, Carli F. The physiological effects of thoracic epidural anesthesia and analgesia on the cardiovascular, respiratory and gastrointestinal systems. Minerva Anesthesiol 2008;74(10):549-563.

9. Scarci M, Joshi A, Attia R. In patients undergoing thoracic surgery is paravertebral block as effective as epidural analgesia for pain management? Interact CardiovascThoracSurg 2010; 10(1):92-96.

10. Freise H, Van Aken HK. Risks and benefits of thoracic epidural anaesthesia. Br J Anaesth 2011;107(6):859-868.

11. Holcomb JB, McMullin NR, Kozar RA, Lygas MH, Moore FA. Morbidity from rib fractures increases after age 45. J Am CollSurg 2003;196(4):549-555.

12. Teoh DA, Santosham KL, Lydell CC, Smith DF, Beriault MT. Surface anatomy as a guide to vertebral level for thoracic epidural placement. AnesthAnalg 2009;108(5):1705-1707.

13. Wong-Baker FACES $\AA$ Pain Rating Scale. Retrieved from: https://wongbakerfaces.org/ (accessed on January 7, 2013).

14. Parris R. Towards evidence-based emergency medicine: best BETs from the Manchester Royal Infirmary. Epidural analgesia/anaesthesia versus systemic intravenous opioid analgesia in the management of blunt thoracic trauma. Emerg Med J 2007;24(12):848-849.

15. Testerman GM. Adverse outcomes in younger rib fracture patients. South Med J 2006;99(4):335-339.

16. Mezue WC, Ndubuisi CA, Erechukwu UA, Ohaegbulam SC. Chest injuries associated with head injury. Niger J Surg 2012;18(1):8-12.

17. Worthley LI. Thoracic epidural in the management of chest trauma: A study of 161 cases.Intensive Care Med 1985; 11(6):312-315. 